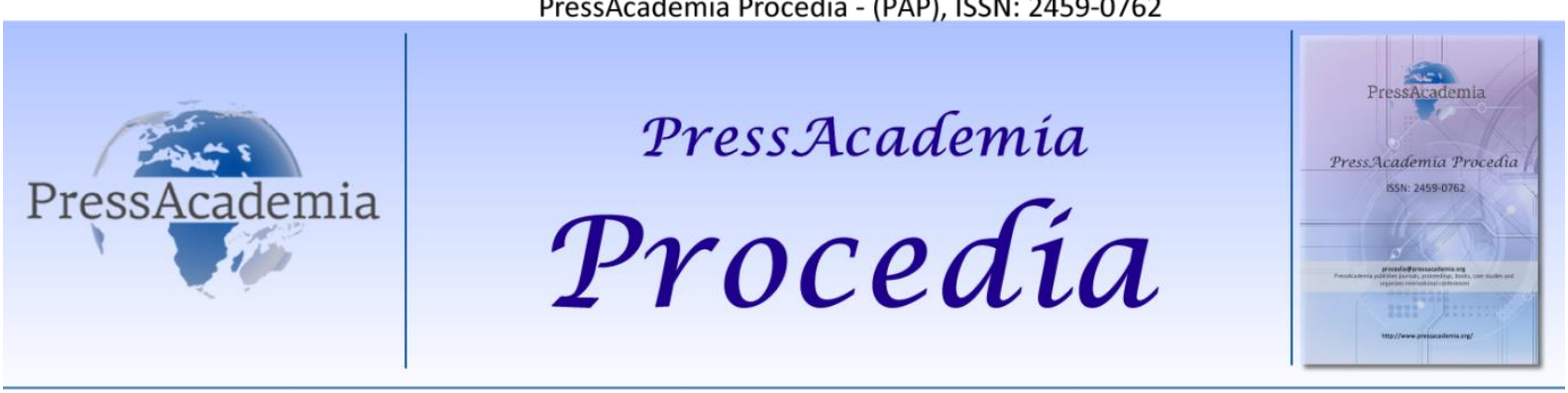

2nd World Conference on Technology, Innovation and Entrepreneurship

May 12-14, 2017, Istanbul, Turkey. Edited by Sefer Şener

\title{
SAFETY SHOES WEARER'S COMFORT PERCEPTION AND EFFECTS AMONG MANUFACTURING EMPLOYEES
}

DOI: 10.17261/Pressacademia.2017.599

PAP-WCTIE-V.5-2017(37)-p.270-273

Baba Md Deros ${ }^{1}$, Mohd lezalman Ab Rahman ${ }^{1}$, Nurul Huda Baba ${ }^{1}$ \& Ahmed Rithauddeen Yusof ${ }^{1}$

${ }^{1}$ Universiti Kebangsaan Malaysia

\begin{abstract}
This study investigates ergonomic problems faced by manufacturing employees due to wearing inappropriate safety shoes. A total of 30 survey respondents was recruited based on the shoes they wear. Pedar- $X$ was used in the experiment to measure the pressure that acts on the wearer' feet. Survey results showed the wearer' experienced the highest pain with the frequency of $80 \%$ for right and $83.33 \%$ for the left heel for wearing safety shoes two to three times a week. Meanwhile, Pedar-X recorded average peak pressure, force and surface area: Amporlo, $90.53 \mathrm{kPa}, 259.57 \mathrm{~N}$, and $67.74 \mathrm{~cm} 2$; Land Master, $75.07 \mathrm{kPa}, 273.79 \mathrm{~N}$ and $72.65 \mathrm{~cm} 2$; Jack Parcell ordinary flat, $67.85 \mathrm{kPa}$, $170.68 \mathrm{~N}$ and $52.08 \mathrm{~cm} 2$ respectively. It was found strain on the front and middle of the feet were lowest. Meanwhile, the back foot, which locates the heel recorded the highest pressure value of $185 \mathrm{kPa}$ as a result of wearing inappropriate safety shoes.
\end{abstract}

Keywords: Peak pressure, force, surface area, foot, comfort

\section{INTRODUCTION}

There is a wide range of safety shoes designed and used in the workplace depending on the existing hazard. It can be divided into three categories, such as safety, protective and occupational shoes. Safety shoes are made of various materials and are equipped with a special internal protection element, such as toecap, metatarsal anti-stress, ankle protector and anti-penetration are installed in the safety shoes (Irzmańska, 2014; ISO 20344, 2012) for foot protection from impact and pressure. These protective elements are made from different materials, which includes steel, aluminum, plastic and composite (Koradecka and Konarska, 2002).

\section{LITERATURE REVIEW}

The foot is primarily supported by the plantar surface. Figure 1 shows the definition of the six plantar surface regions. For example, when a person is standing (i.e. the inside of a shoe), there will be interaction between the plantar surface of the foot and the surface on which the person stands. The interaction between the plantar surface, dorsal surface of the foot and the load-bearing surface, the whole body posture contributes to foot and surface deformations and hence to perceived comfort, discomfort, pain or fatigue (Witana et al. 2009; Cham and Redfern, 2001; Kelaher et al. 2000; King, 2002). High plantar pressures have been linked to foot pain and discomfort (Gardner et al. 1988; Hodge et al. 1999). Other factors that could contribute towards comfort are firmness, anthropometric features and pressure distributions ( $\mathrm{Na}$ et al. 2005).

In manufacturing industries, safety shoes are specially designed for employees to wear to protect their foot from workplace hazards such as rolling, falling or sharp objects. The basic functions of safety shoes are to provide protection the foot against hazards present at the workplace (Irzmańska, 2014; Koradecka (2010). There are various types of safety shoes have been specially designed for use in factories and in other industries. Safety shoes have a wide variety of designs and each type of safety shoes manufactured has its own advantages and disadvantages. In addition, the design of appropriate safety shoes for various industrial sectors, professions, and work positions need to meet all requirements with respect to ergonomic and protective properties, durability, hygiene, comfort for use and functionality to avoid the occurrence of foot pain and injury in the workplace (Dobson et al. 2017; Koradecka, 2012). 
Figure 1: Definition of the Six Plantar Surface Regions (Hong et al. 2005).

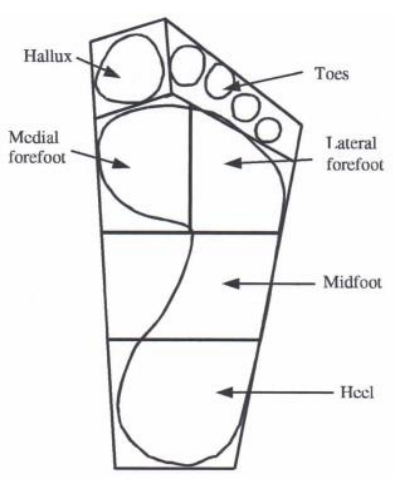

On average, the majority of employees working in the manufacturing industries spent a total of eight hours per day or more. While working, for example, an operator in semiconductors or in the automotive manufacturing factory, employees usually work in prolonged sitting and standing postures. Wearing inappropriate safety shoes will negatively affect the comfort level of an employee. Thus, the two main objectives of this study are to review and evaluate the overall effects of wearing of safety shoes to employees.

\section{DATA AND METHODOLOGY}

\subsection{Respondents}

The study population is employees from manufacturing industry itself. They were selected due to their positions, such as the factory managers, executives, engineers, safety officers and supervisors from the plant.

\subsection{Data Collection}

The survey questionnaire comprised of three parts; socioeconomic status, risk factors, and prevalence of pain in the lower part of the body. A survey questionnaire was given to selected respondents in the manufacturing industries. Every respondent was given the explanation and guidance on how to complete the survey questionnaire.

\subsection{Pedar-X System}

Pedar-X system data collection method was used to determine the shoe pressure. This method used an insole or a liner attached with a sensor that can measure the amount of pressure in a shoe. In this study, data was collected while the subject is standing in the upright position only (Ramanathan et al. 2010). During the experiment, subjects were asked to wear three different types of shoes. The main purpose of this experiment was to measure and determine data distribution experienced by the wearer of the shoes.

Parameters considered in this method are contacted area, contact time, maximum force, pressure-time integral, forcetime integral, peak pressure, mean force and mean area. However, to simplify the data collection in this study, only a few parameters were taken, which include peak pressure, force and mean area. Having done that, comparisons were made for all the three types of shoes selected. Figure 2 shows the experimental set-up preparation for Pedar-X System.

\section{Figure 2: Preparation for Pedar-X System Device}

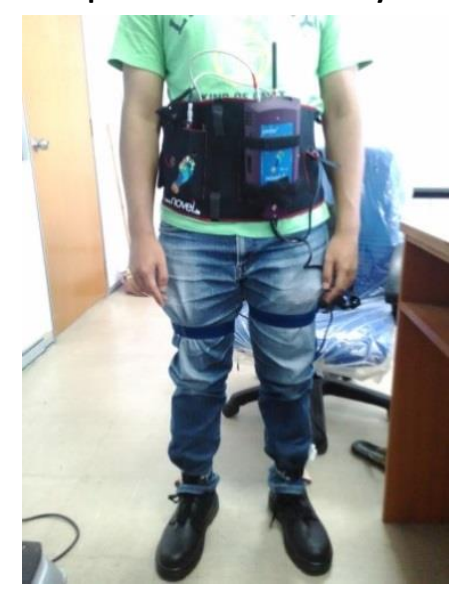




\section{FINDINGS AND DISCUSSIONS}

\subsection{Survey Questionnaire Results}

Based on Cornell analysis found in the survey questionnaire, the impact of safety shoe application showed pain commonly occurs at the left and right heel with a total average prevalence of $81.67 \%$ and pain occurs as a result of their standing work posture. Part of the calf showed the relatively high average prevalence of pain at $51.67 \%$. Meanwhile, the hips showed the lower average prevalence of pain at $26.67 \%$ compared to other body parts. Other parts of the body, such as the neck, shoulders, back, arms, hips, wrists, buttocks, hips, and knees are not affected with the wearing of safety shoes.

The survey result shows that when the work is done while standing, the pressure of the shoes will be higher than the pressure on the shoes while sitting. This is the main cause why parts of the heel have a high percentage of the pain after wearing safety shoes. Employees at this automotive car body assembler work at different workstations. Each worker has to install different car components, where he or she has to stand upright while installing each component in the vehicle.

\subsection{Pedar-X System Analysis}

Data analysis using the Pedar-X system was conducted on three different types of shoes, two of them were safety shoes (i.e. Amporlo and Land Master) and the third one is ordinary flat shoes (i.e. Jack Parcell). Normal data distribution from the Pedar-X system for Amporlo safety shoes shows that the peak pressure was $82.5 \mathrm{kPa}$, the force of $243.77 \mathrm{~N}$ and surface area $67.33 \mathrm{~cm}^{2}$. For Land Master safety shoes, the peak pressure was $67.5 \mathrm{kPa}$, the force of $224.363 \mathrm{~N}$ and surface area $72.17 \mathrm{~cm}^{2}$. Jack Parcell the flat shoes indicate the peak pressure of $60 \mathrm{kPa}$, force $163.193 \mathrm{~N}$ and surface area $48.67 \mathrm{~cm}^{2}$.

Experimental results as shown in Figure 3, when the subject was wearing Amporlo safety shoes, the pressure distribution data recorded at foot front was $88 \mathrm{kPa}$, at the middle part of the foot was $15 \mathrm{kPa}$, and at the back of the foot (i.e. heel) was $185 \mathrm{kPa}$. Meanwhile, for Land Master safety shoes as shown in Figure 4, the pressure distribution data recorded at the foot front was $88 \mathrm{kPa}$, at the middle part of the foot was $15 \mathrm{kPa}$, and at the back foot (i.e. heel) was $160 \mathrm{kPa}$. For Jack Parcell normal flat shoes as shown in Figure 5 the pressure distribution data readings recorded the front of the foot was $50 \mathrm{kPa}$; at the middle part of the foot was $15 \mathrm{kPa}$, and at the back foot (i.e. heel) was $83 \mathrm{kPa}$.

Figure 3: Pressure Distribution Recorded on the Subject's Foot When Wearing Amporlo Safety Shoes

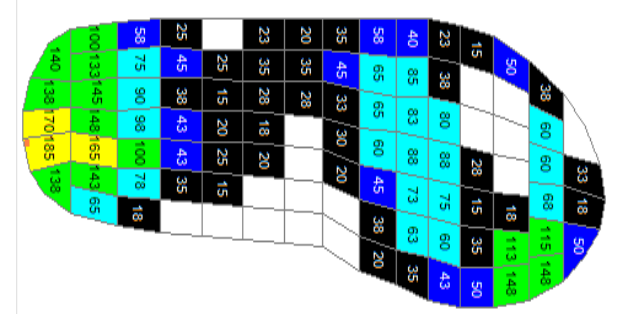

Figure 4: Pressure Distribution Recorded on the Subject's Foot When Wearing Land Master Safey Shoes

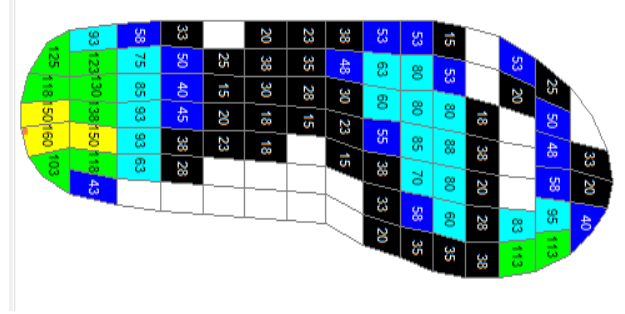


Figure 5: Pressure Distribution Recorded on the Subject's Foot When Wearing Ordinary Flat Shoes

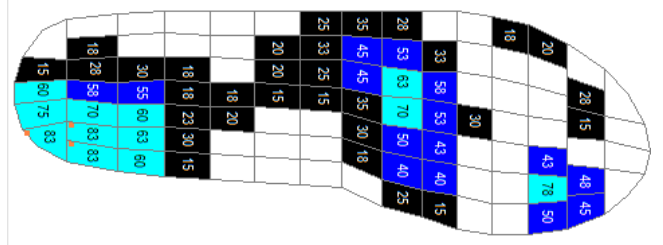

\section{CONCLUSION}

Based on the data found in the survey conducted, the impact of wearing safety shoes resulted in pain at left and right heel with a total average prevalence of $81.67 \%$ due to their standing work posture. The heel recorded the highest pressure distribution data when wearing all the three shoe types: Amporlo safety shoes, $185 \mathrm{kPa}$; Land Master safety shoes, $160 \mathrm{kPa}$; and Jack Parcell normal flat shoes, $83 \mathrm{kPa}$. Meanwhile, the pressure distribution data recorded at the foot front when wearing: Amporlo safety shoes, $88 \mathrm{kPa}$; Land Master safety shoes, $88 \mathrm{kPa}$; and Jack Parcell normal flat shoes, $50 \mathrm{kPa}$. The pressure distribution recorded at middle of the foot when wearing both safety shoes and ordinary flat shoes were the lowest and all three different shoes recorded the same value, which is at $15 \mathrm{kPa}$. When compared with data from the Pedar$x$ system, proved that the strain on the front and middle of the feet are the lowest and when compared with data from the Pedar-x system, also proved that the pressure on the back of the legs which is the heel, highest with the value of $185 \mathrm{kPa}$.

\section{REFERENCES}

Cham, R., Redfern, M.S., 2001, “Effect of flooring on standing comfort and fatigue, Human Factors”, vol. 43, no. 3, pp. 381-391.

DeVocht, J.W., Wilder, D.G., Bandstra, E.R., Spratt, K.F., 2006, “Biomechanical evaluation of four different mattresses”, Appl. Ergon., vol. 37, no. 3, pp. 297-304.

Dobson, J.A., Riddiford-Harland, D. L., Bell, A.F. \& Steele, J.R. 2017, “Effect of work boot type on work footwear habits, lower limb pain and perceptions of work boot fit and comfort in underground coal miners", Applied Ergonomics, vol. 60, pp. 146-153.

Gardner, L.I., Dziados, J.E., Jones, B.H., 1988, "Prevention of lower extremity stress fractures: a controlled trial of a shock absorbent insole", Am. J. Public Health, vol. 78, pp. 1563-1567.

Hodge, M.C., Bach, T.M., Carter, G.M., 1999. “Orthotic management of plantar pressure and pain in rheumatoid arthritis, Clin. Biomech, vol. 14, pp. 567-575.

Hong, W. H., Lee, Y. H., Chen, H. C., Pei, Y. C., \& Wu, C. Y. 2005, "Influence of heel height and shoe insert on comfort perception and biomechanical performance of young female adults during walking. Foot \& ankle international, vol. 26, no. 12, pp. 1042-1048.

Irzmańska, E. 2014, "Footware use at workplace and recomendations for the improvement of its functionality and hygiene", AUTEX Research Journal, vol. 14, no. 2, pp. 89-94.

ISO 20344, 2012. Personal Protective Equipment. Test Methods for Footwear.

Kelaher, D., Mirka, G.A., Dudziak, K.Q., 2000. Effects of semi-rigid arch-support orthotics: an investigation with potential ergonomic implications. Appl. Ergon. 31 (5), 515-522.

King, P.M., 2002, “A comparison of the effects of floor mats and shoe in-soles on standing fatigue”, Appl. Ergon., vol. 33, no. 5, pp. 477484 .

Koradecka D. 2012, “Use of Personal Protective Equipment in the Workplace. In: Handbook of Human Factors and Ergonomics", USA: John Wiley \&Sons Press 2012, pp. 895-910.

Koradecka, D., 2010. Handbook of Occupational Safety and Health. CRP Press Taylor \& Francis Group, USA.

Koradecka, D., Konarska, M., 2002, "Advance in physiology and ergonomics and their impact on th hygiene of work", Medycyna Pracy (Occup. Med. - in Polish), vol. 53, no. 1, pp. 15-21.

Na, S., Lim, S., Choi, H.S., Chung, M.K., 2005, "Evaluation of driver's discomfort and postural change using dynamic body pressure distribution", Int. J. Ind. Ergon, vol. 35, no. 12, pp. 1085-1096.

Ramanathan, A. K., Kiran, P., Arnold, G. P., Wang, W., \& Abboud, R. J., 2010, "Repeatability of the Pedar-X® in-shoe pressure measuring system, Foot and Ankle Surgery, vol. 16, no. 2, pp. 70-73.

Witana, C. P., Goonetilleke, R. S., Xiong, S., \& Au, E. Y., 2009, “Effects of surface characteristics on the plantar shape of feet and subjects' perceived sensations", Applied Ergonomics, vo. 40, no. 2, pp. 267-279. 